\title{
Dissection of Prp8 protein defines multiple interactions with crucial RNA sequences in the catalytic core of the spliceosome
}

\author{
IAN A. TURNER, CHRISTINE M. NORMAN, MARK J. CHURCHER, and ANDREW J. NEWMAN \\ MRC Laboratory of Molecular Biology, Cambridge CB2 2QH, UK
}

\begin{abstract}
Current models of the core of the spliceosome include a network of RNA-RNA interactions involving the pre-mRNA and the U2, U5, and U6 snRNAs. The essential spliceosomal protein Prp8 interacts with U5 and U6 snRNAs and with specific pre-mRNA sequences that participate in catalysis. This close association with crucial RNA sequences, together with extensive genetic evidence, suggests that Prp8 could directly affect the function of the catalytic core, perhaps acting as a splicing cofactor. However, the sequence of Prp8 is almost entirely novel, and it offers few clues to the molecular basis of Prp8-RNA interactions. We have used an innovative transposon-based strategy to establish that catalytic core RNAs make multiple contacts in the central region of Prp8, underscoring the intimate relationship between this protein and the catalytic center of the spliceosome. Our analysis of RNA interactions identifies a discrete, highly conserved region of Prp8 as a prime candidate for the role of cofactor for the spliceosome's RNA core.
\end{abstract}

Keywords: spliceosome; Prp8; RNA-protein interaction; pre-mRNA splicing

\section{INTRODUCTION}

Pre-mRNA splicing in eukaryotes is catalyzed by the spliceosome, a dynamic complex consisting of five small nuclear RNAs (snRNAs) and multiple proteins. The chemical mechanism of pre-mRNA splicing is identical to that of self-splicing Group II introns and involves two trans-esterification reactions. In the first reaction the $2^{\prime} \mathrm{OH}$ of a specific adenosine in the intron, termed the branch point (BP), attacks the $5^{\prime}$ splice site (SS), producing a branched or "lariat" intron intermediate and a 5 'exon intermediate with a $3^{\prime} \mathrm{OH}$ group. In the second reaction this $3^{\prime} \mathrm{OH}$ group attacks the $3^{\prime} \mathrm{SS}$ to produce lariat intron and spliced mRNA products. The catalytic core of the spliceosome consists of a highly structured RNA network formed between U2, U6, and U5 snRNAs and the sites of chemistry in the pre-mRNA (Parker et al. 1987; Wu and Manley 1989; Newman and Norman 1992; Kandels-Lewis and Seraphin 1993; Lesser and Guthrie 1993; Sontheimer and Steitz 1993). Mechanistic and structural similarities between the

Reprint requests to: Andrew J. Newman, MRC Laboratory of Molecular Biology, Hills Road, Cambridge CB2 2QH, UK; e-mail: newman@mrclmb.cam.ac.uk; fax: 441223412142 .

Article published online ahead of print. Article and publication date are at http://www.rnajournal.org/cgi/doi/10.1261/rna.2229706. spliceosomal snRNAs and Group II autocatalytic introns strongly support the hypothesis that spliceosomal snRNA sequences are central to the catalysis of pre-mRNA splicing (Moore and Sharp 1993; Padgett et al. 1994; Boulanger et al. 1995; Peebles et al. 1995; Sigel et al. 2000; Villa et al. 2002; Hilliker and Staley 2004). In particular an RNA complex between $\mathrm{U} 2$ and U6 snRNAs is believed to play a critical role in the catalytic core of the spliceosome, acting as a scaffold to juxtapose the reactive 5'SS and BP sequences and to position a bound metal ion that is essential for splicing catalysis (Madhani and Guthrie 1992; Sun and Manley 1995; Yean et al. 2000; Huppler et al. 2002; Sashital et al. 2004). Indeed a synthetic, protein-free U2-U6 snRNA complex formed in the presence of $\mathrm{Mg}^{2+}$ ions is able to promote a reaction similar to the first transesterification reaction of splicing (Valadkhan and Manley 2001).

In contrast to the detailed structural and mechanistic information now available for the RNA components of the spliceosome's catalytic core, there is much less information about the possible contributions of protein factors to catalytic core structure and activity. However, one spliceosomal protein-the U5 snRNP component Prp8-has attracted attention because it has been shown to contact multiple catalytic core RNA residues. Crucially, it has been cross-linked to sequences at or near the 5'SS, BP, and 3'SS, i.e., all three of the substrate sequences involved in the 
transesterification reactions (Wyatt et al. 1992; Teigelkamp et al. 1995; Umen and Guthrie 1995b; Chiara et al. 1996, 1997; Reyes et al. 1996, 1999; Maroney et al. 2000; McPheeters and Muhlenkamp 2003), and is also known to contact critical residues in U5 and U6 snRNAs (Dix et al. 1998; Vidal et al. 1999). Prp8 is intimately involved in the RNA rearrangements that are required for formation of the catalytic core RNA structures (Kuhn et al. 1999, 2002; Kuhn and Brow 2000; van Nues and Beggs 2001). Genetic studies have shown that multiple prp8 alleles give a complex pattern of suppression of mutations in the 5'SS, BP, and 3'SS sequences (Umen and Guthrie 1995a, 1996; Collins and Guthrie 1999; Siatecka et al. 1999; Query and Konarska 2004). Clearly this protein occupies a pivotal position in the core of the spliceosome, and this has led to speculation that Prp8 might act as a splicing cofactor, perhaps by stabilizing catalytic core RNA structures, or alternatively Prp8 could itself contribute functional groups to the spliceosome's active site (Collins and Guthrie 2000).

The sequences of many Prp8 orthologs are now available, but they have little obvious homology to other protein domains, so they offer few clues to the protein's possible biochemical functions or domain organization. Overall Prp8 is highly conserved in both size and sequence: Most orthologs are $\sim 2400$ residues long and there is $61 \%$ identity between the yeast and human sequences (Hodges et al. 1995; Luo et al. 1999). With regard to Prp8's RNA interactions, the clearest feature to emerge from sequence analysis is a putative RNA recognition motif (RRM) in the central region of the protein (Grainger and Beggs 2005). The RRM is a potential binding site for one or more of the protein's known RNA partners in the core of the spliceosome, but its actual ligand has yet to be identified. The only Prp8-RNA contact mapped so far is between the $5^{\prime} \mathrm{SS}$ and the human ortholog of Prp8, and lies near the $\mathrm{C}$ terminus of the protein, remote from the RRM (Reyes et al. 1999).

Here we have used site-specific RNA-protein photocrosslinking together with a novel proteolytic strategy to resolve and physically map multiple contacts between $\operatorname{Prp} 8$ and important catalytic core RNA sequences. The mapping strategy involves the insertion of short peptide tags containing protease sites into Prp8 using a custom-built Tn5-based transposon. Insertion of peptide tags was tolerated at many sites in Prp8 without compromising any of the protein's essential functions. The sites of RNA-protein cross-links on Prp8 were then determined using this array of protease sites. This approach has the power to dissect and resolve complex patterns of cross-links. We show that three noncontiguous regions of Prp 8 contact both the 5'SS and BP in spliceosomes. The data highlight a short, highly conserved segment of Prp8 as a prime candidate for the role of promoting RNA catalysis in the spliceosome. This new information about Prp8's RNA interactions will be invaluable for the design of experiments aimed at reconstituting the spliceosome's catalytic center for structural and functional analysis.

\section{RESULTS}

\section{Insertion of TEV protease sites into Prp8}

Transposon mutagenesis of PRP8 produced a library of genes, each containing a single copy of the 69-bp insert containing a TEV protease site. Analysis of the library by restriction enzyme digestion (data not shown) revealed that, prior to screening for function, the transposons were broadly distributed throughout the gene without obvious clustering. This is consistent with earlier data on Tn5 indicating that transposition is highly random (Shevchenko et al. 2002). An initial small-scale plasmid shuffle screen isolated the genes for 25 functional TEV site-tagged Prp8 proteins, and in this cohort the TEV inserts mapped to six main clusters arranged nonrandomly across the gene (Fig. 1A). In view of the highly random nature of the primary transposon library, this clustering of the survivors of the screen probably reflects selection against TEV inserts in specific regions of the protein: for example, the transposon-free interval 1503-1673. Indeed extensive screening for transposon inserts in this region produced no survivors, and several TEV inserts introduced into the 1503-1673 interval by site-directed mutagenesis proved to be lethal in every case (data not shown). This suggests that the 15031673 interval and perhaps other regions of $\operatorname{Prp} 8$ are particularly sensitive to foreign sequence insertions.

Analysis of several splicing extracts made from strains with TEV sites in Prp8 showed that these extracts displayed normal splicing activity, and that incubation with TEV protease in native conditions resulted in highly specific cleavage of Prp8 at inserted TEV sites. Initial mapping suggested that Prp8-RNA cross-links were present in the central region of the protein, where there were extensive transposon-free areas. To facilitate the characterization and mapping of RNA interactions in Prp8, we therefore searched for additional prp8 alleles with TEV inserts in the central part of the gene. This entailed new transposon screens focused on this region and targeted mutagenesis of regions expected to form exposed surface loops (by secondary structure prediction using Predict Protein) or sites known to harbor inserts in other Prp8 orthologs (Grainger and Beggs 2005). Together these approaches produced an extensive collection of functional prp8 alleles with protease cleavage sites in the central region of the protein (Fig. 1A). We have used these engineered proteins to analyze contacts between $\operatorname{Prp} 8$ and important residues in the pre-mRNA, U5 snRNA, and U6 snRNA.

\section{U6 snRNA contacts the highly conserved domain 3.2 of Prp8}

Contact between Prp8 and U6 snRNA in U4/U6.U5 trisnRNPs was originally demonstrated (Vidal et al. 1999) by incorporating a 4-thiouridine (4-thioU) photocross-linker at position 54 in U6. This nucleotide is immediately 

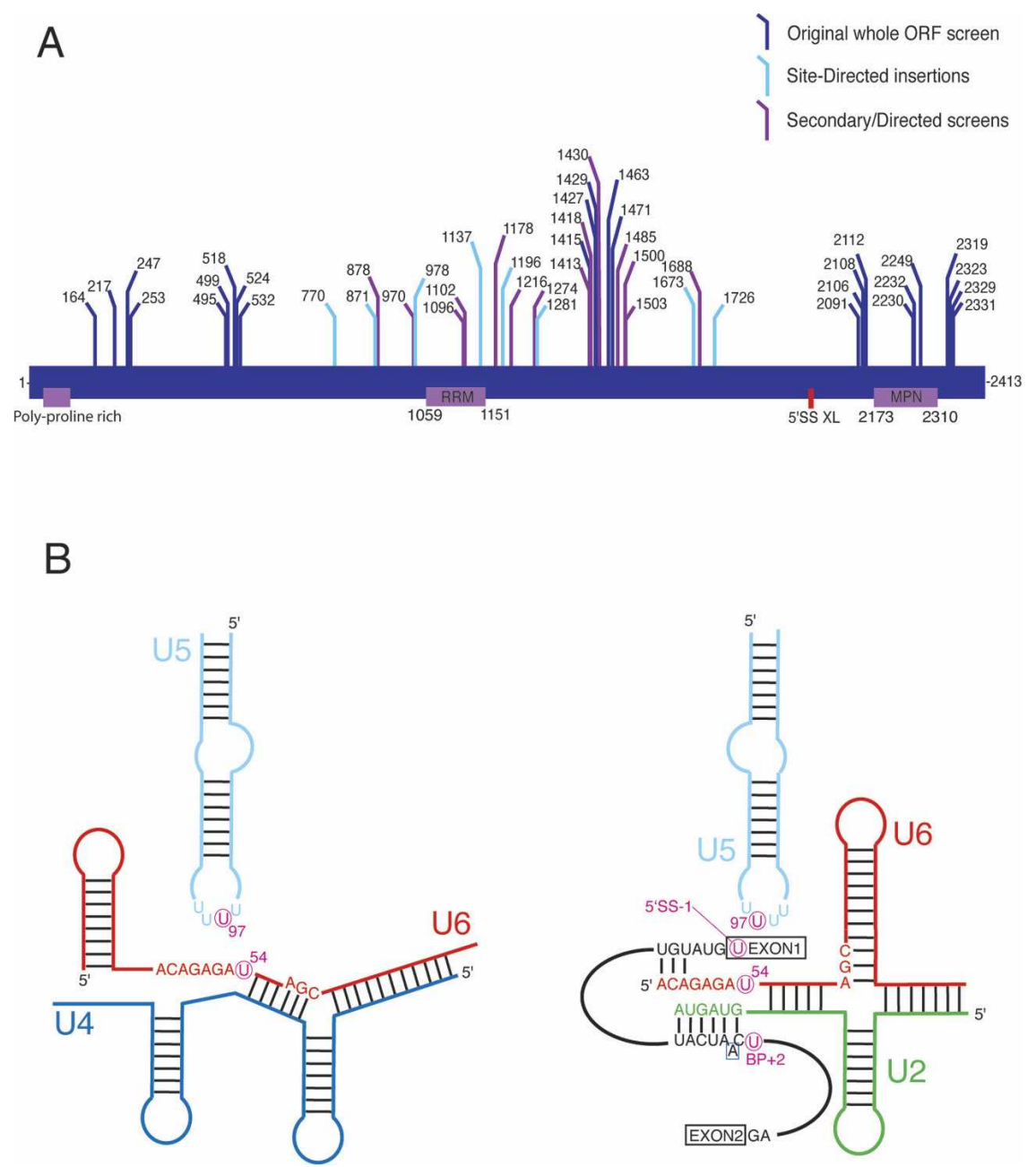

FIGURE 1. Positions of TEV protease sites in Prp8 and 4-thioU residues in U5 snRNA, U6 snRNA, and the pre-mRNA. $(A)$ TEV sites are numbered according to the Prp 8 amino acid immediately upstream of the peptide insert. The locations of conserved RNA recognition motif (RRM) and Mpr-1, Pad1, N-terminal (MPN) domains and the N-terminal proline-rich region (Grainger and Beggs 2005) are also shown. (B) Predicted RNA secondary structures in U4/ U6.U5 tri-snRNPs (left) and spliceosomes (right). The positions of 4-thioU photocross-linkers in U5 snRNA (nucleotide 97 in Loop 1), U6 snRNA (nucleotide 54), and the pre-mRNA (5'SS1 and $\mathrm{BP}+2)$ are indicated.

downstream of the conserved ACAGAG motif that contacts the $5^{\prime}$ splice site in the spliceosome and also lies at the end of one of the U4-U6 helices in the U4/U6.U5 tri-snRNP. U6 snRNA with a single ${ }^{32} \mathrm{P}$-labeled phosphate upstream of a 4 -thioU at position 54 was synthesized by ligation and demonstrated to reconstitute functional snRNP particles by splicing activity assay (data not shown). As shown previously (Vidal et al. 1999) we detected cross-links from U54 in U6 snRNA to two large polypeptides, both with apparent molecular weights $>200$ $\mathrm{kDa}$, after UV irradiation, affinity capture, and SDS-PAGE (Fig. 2A). Mobility shifts according to the presence or absence of epitope tags (data not shown) confirmed that the upper of these proteins is $\operatorname{Prp} 8$ and the lower is Brr2, which, like Prp8, is a component of U5 snRNP and the U4/U6.U5 tri-snRNP. $\mathrm{Brr} 2$ is involved in unwinding U4-U6 base pairing prior to catalytic activation of the spliceosome (Laggerbauer et al. 1998; Raghunathan and Guthrie 1998; Kim and Rossi 1999; Kuhn and Brow 2000). The formation of these RNA-protein cross-links is strictly dependent on the presence of the 4-thioU photocrosslinker, demonstrating that they are indeed site specific (data not shown). When cross-linked samples from extracts with TEV sites at various positions in Prp8 are split into two aliquots, incubated in the absence and presence of TEV protease, and fractionated by SDSPAGE, a single novel labeled species appears in each $+\mathrm{TEV}$ protease lane, corresponding to the predicted mobility of one of the TEV digestion products (Fig. 2A). For TEV sites at positions 1281, 1471 , and 1503 , it is the C-terminal fragment that is labeled, while for TEV sites at 1673,1688 , and 1726 , the N-terminal fragment is labeled. These results show that U6 [U54] makes contact(s) between amino acids 1503 and 1673 in the Prp8 sequence, an interval that overlaps extensively with domain 3.2 of Prp8, a region of exceptional sequence conservation (Grainger and Beggs 2005).

\section{U5 snRNA contacts two discrete segments of Prp8}

Prp8 has been shown to make extensive contacts with U5 snRNA in reconstituted yeast U5 snRNPs (Dix et al. 1998) and cross-linked strongly to a 4 -thioU photocross-linker at nucleotide 97 in the invariant Loop 1 sequence. This loop is known to contact the $5^{\prime}$ and $3^{\prime}$ exon sequences adjacent to the splice sites in active spliceosomes (Newman and Norman 1992; Wyatt et al. 1992; Cortes et al. 1993; Sontheimer and Steitz 1993; Newman et al. 1995). Using U5 snRNA with a single ${ }^{32} \mathrm{P}$-labeled phosphate and 4-thioU at position 97 in Loop 1, we assembled U5 snRNPs in several splicing extracts with TEV sites at different positions in Prp8 (Fig. 2B). The U5 snRNP reconstitution procedure used here does not support U4/U6.U5 tri-snRNP formation, so our analysis is aimed at U5 snRNA-Prp8 crosslinks formed solely in U5 snRNPs (see Materials and Methods). After UV irradiation, affinity capture, and SDS-PAGE, a closely spaced doublet of labeled proteins of apparent molecular weight $>200 \mathrm{kDa}$ is visible in each extract. Formation of 
A
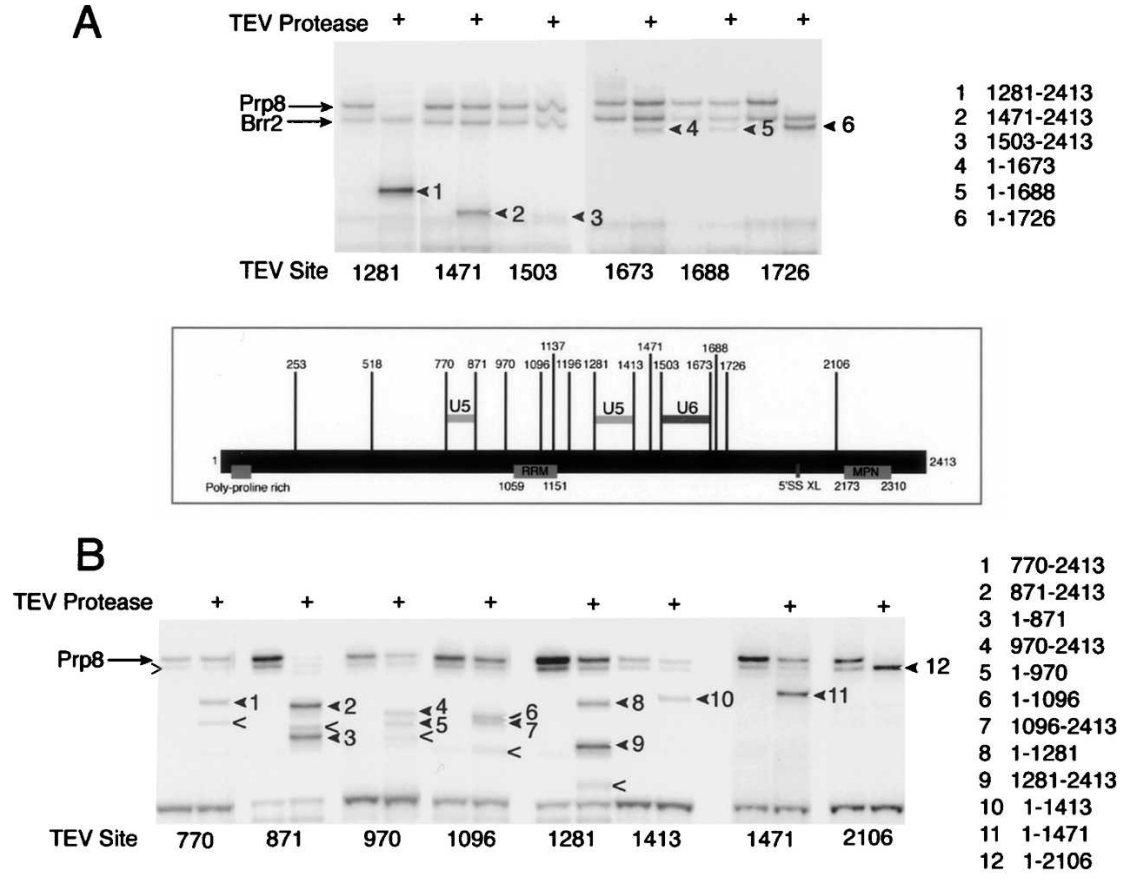

C
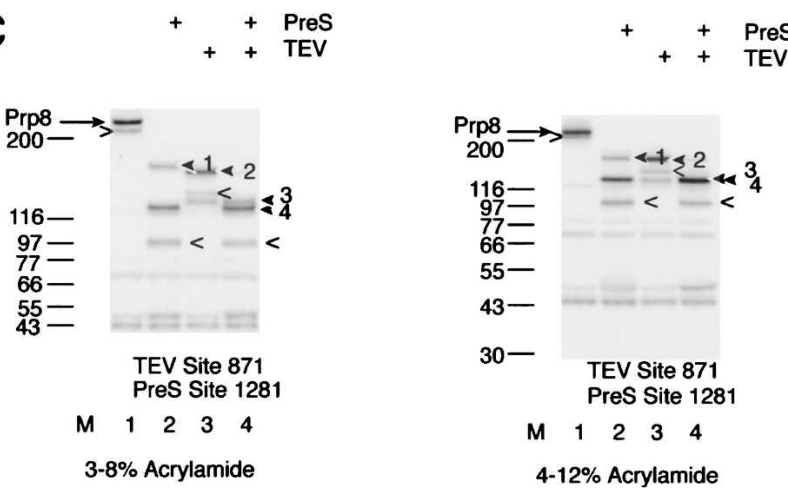

1 1-1281 $2871-2413$

3 1-871

4 1281-2413
$1 \quad 1281-2413$

2 1471-2413

3 1503-2413

$\begin{array}{ll}4 & 1-1673 \\ 5 & 1-1688\end{array}$

$\begin{array}{ll}6 & 1.1726\end{array}$

FIGURE 2. Prp8 interactions with U5 and U6 snRNAs. (A) Analysis of cross-links between Prp8 and nucleotide 54 of U6 snRNA in U4/U6.U5 tri-snRNPs by cleavage at TEV protease sites (at the amino acid indicated below each pair of lanes) in Prp8. After cross-linking and capture, the samples were divided into two aliquots and incubated with or without TEV protease before fractionation by SDS-PAGE and visualization by phosphorimaging. ${ }^{32} \mathrm{P}$-labeled Prp8 fragments released by TEV protease cleavage are indicated by arrowheads (1-6) and identified on the right. It is clear that the TEV sites at 1503-1688 are partially resistant to protease cleavage. Therefore we cannot exclude the possibility that additional cross-link(s) might be present outside the 15031673 region (but between 1281 and 1726) in a subpopulation of Prp8 that is wholly resistant to TEV protease digestion. (B) Analysis of cross-links between Prp8 and nucleotide 97 of U5 snRNA by cleavage at TEV protease sites in Prp8. Samples were divided into two aliquots and incubated with or without TEV protease before fractionation by SDS-PAGE and visualization by phosphorimaging. ${ }^{32} \mathrm{P}$-labeled Prp8 fragments released by TEV protease cleavage are indicated by arrowheads (1-12) and identified on the right. Open arrowheads indicate ${ }^{32} \mathrm{P}$-labeled Prp8 fragments truncated near the $C$ terminus (in the vicinity of position 2100-2200) by an endogenous protease (see Results). (C) Analysis of cross-links between Prp8 and nucleotide 97 of U5 snRNA using Prp8 with a TEV protease site at 871 and a PreScission (PreS) protease site at 1281. After crosslinking and capture, the sample was divided into four aliquots and incubated in the presence of proteases as indicated before fractionation by SDS-PAGE and visualization by phosphorimaging. The positions and sizes (in kilodaltons) of unlabeled molecular weight markers are shown to the left of each gel. ${ }^{32} \mathrm{P}$-labeled Prp8 fragments released by TEV and/or PreS protease cleavage are indicated by arrowheads (1-4) and identified on the right. Open arrowheads indicate ${ }^{32} \mathrm{P}$-labeled Prp8 fragments truncated near the $\mathrm{C}$ terminus by an endogenous protease (see Results). (Inset) Cartoon of the Prp8 protein, showing the array of TEV sites and summarizing the cross-link mapping data presented in $A-C$.

these RNA-protein cross-links is strictly dependent on the presence of the 4-thioU photocross-linker, demonstrating that they are genuinely site specific. The upper band is full-length Prp8 and the lower component (open arrowhead) results from cleavage by an endogenous protease in the vicinity of amino acids 2100-2200 (Fig. 2B; data not shown). Incubation with TEV protease results in the appearance of one or more novel labeled protein bands (Fig. 2B). The pattern is complicated by endogenous protease cleavage of Prp8 that can produce a secondary fragment by C-terminal truncation (open arrowheads in +TEV lanes; see Fig. 2 legend). Taking this complication into account, cleavage at 770, 1413, and 1471 in each case produces a single labeled fragment: 770-2413, 1-1413, and 1-1471, respectively. In contrast, after cleavage at $871,970,1096$, and 1281 , both of the fragments are labeled.

These results indicate that the major cross-links from nucleotide 97 in U5 Loop 1 lie between 770 and 1413 in Prp8. In addition they reveal that there are at least two sites of contact on Prp8: One site maps between 770 and 871 and the other between 1281 and 1413. Clearly, cleavage of Prp8 at any position between 871 and 1281 will result in both polypeptides being labeled and cannot directly address the possibility that additional cross-links might lie in the 871-1281 interval. To address this issue-which is of particular interest in view of the presence of a conserved RRM at residues 1059-1151 of Prp8 (Grainger and Beggs 2005) — we made an additional prp8 allele encoding a protein with a site for TEV protease at 871 and a site for PreScission (PreS) protease (which recognizes the sequence LEVLFQ/GP) at 1281. Cleavage of Prp8 with TEV and PreS proteases separately and in combination gives rise to the predicted labeled polypeptides (Fig. 2C). In particular, the double digest produces labeled 1-871 and 1281-2413 fragments, but the central fragment 871-1281 (predicted molecular weight $51 \mathrm{kDa}$ ) is not detectable on either gel type. In conclusion, these results are consistent with a model in which there are two discrete regions of Prp8 in contact 
with position 97 in U5 Loop 1 (770-871 and 1281-1413). However there is no sign of additional cross-links in the intervening region (871-1281) that includes the conserved Prp8 RRM.

\section{Interactions between Prp8 and the pre-mRNA}

In addition to its contacts with important residues in U5 and U6 snRNAs, Prp8 (and its mammalian ortholog hPrp8) is unique among spliceosomal proteins in that it has been shown to cross-link to all three sequences in the pre-mRNA that participate directly in the chemistry of splicing: the $5^{\prime}$ splice site, branch site, and $3^{\prime}$ splice site (Wyatt et al. 1992; Teigelkamp et al. 1995; Umen and Guthrie 1995a; Chiara et al. 1996, 1997; Reyes et al. 1996, 1999; Maroney et al. 2000; McPheeters and Muhlenkamp 2003). We have used the TEV protease mapping technique to analyze cross-links between Prp8 and several nucleotides in the vicinity of the splice sites and branch site, with the aim of identifying the regions of this protein that may be associated with splicing reaction chemistry.

We have focused on the $5^{\prime}$ splice site and branch point-the two pre-mRNA sequences that the spliceosome must juxtapose in order to catalyze the first transesterification reaction. By incorporating 4-thioU photocross-linkers immediately upstream of the $5^{\prime}$ splice site (position 5'SS-1) or 2 nt downstream of the branch point $(\mathrm{BP}+2)$ in actin pre-mRNAs, we detected cross-links to $\operatorname{Prp} 8$ in active spliceosomes as shown previously (Wyatt et al. 1992; Teigelkamp et al. 1995; Reyes et al. 1996, 1999; Maroney et al. 2000). In each case substrate-Prp8 cross-link formation was strictly dependent on the 4-thioU photocross-linker, and therefore genuinely site-specific (data not shown). Kinetic analysis showed that Prp8 labeling using the 5'SS-1 and BP+2 photocrosslinkers followed similar time courses, peaking after $5 \mathrm{~min}$ of incubation at $23^{\circ} \mathrm{C}$, and coinciding with rapid accumulation of the intermediates and products of splicing (data not shown). In the experiments shown in Figures 3 and 4 , cross-linking was performed after
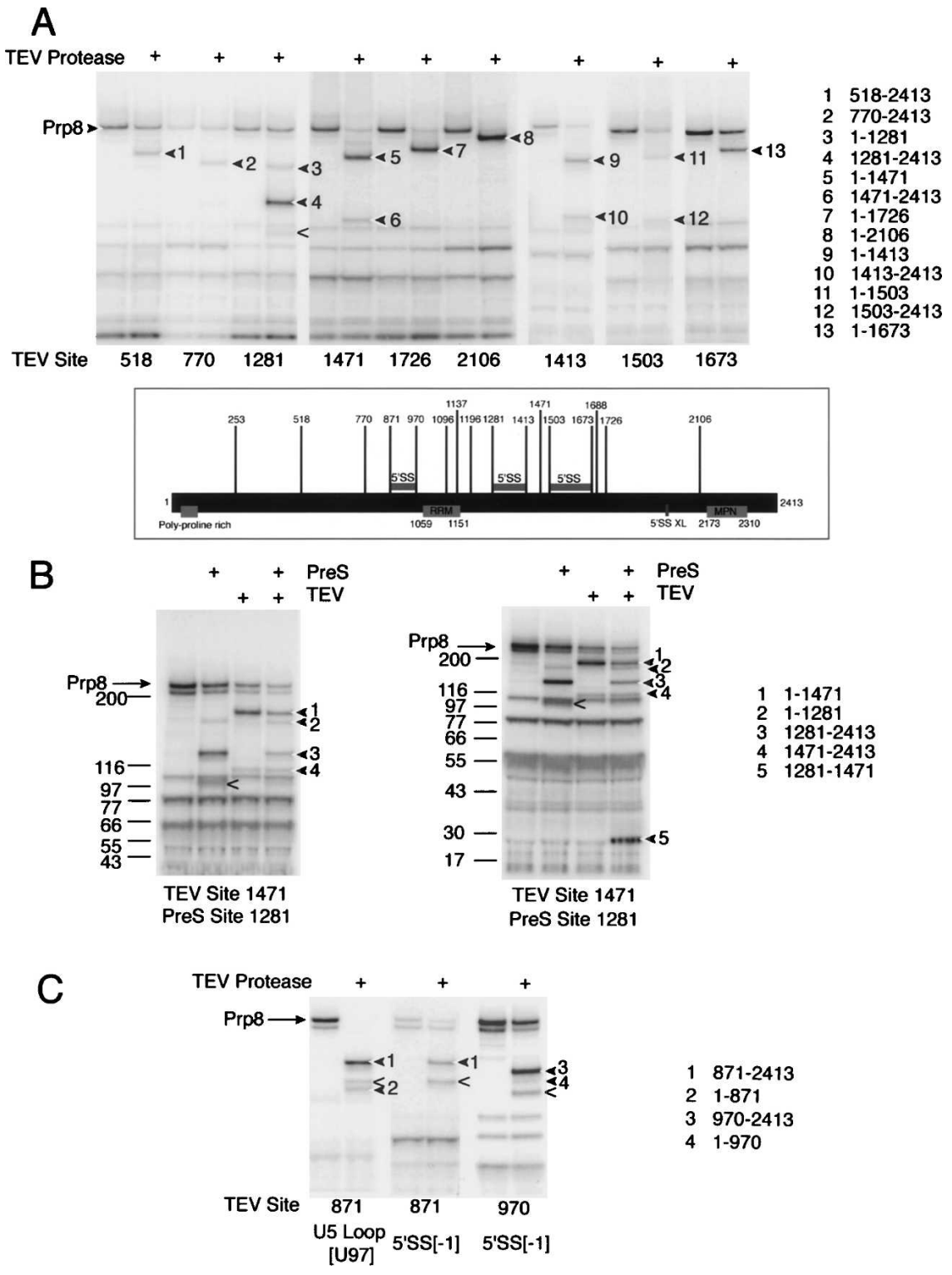

FIGURE 3. Prp8 interactions with the $5^{\prime}$ splice site. (A) Analysis of cross-links between Prp8 and the $5^{\prime}$ SS in actin pre-mRNA, using a photocross-linker at position $5^{\prime}$ SS- 1 . The position of the TEV protease site in Prp8 is indicated below each pair of lanes. After cross-linking and capture, the samples were divided into two aliquots and incubated with or without TEV protease before fractionation by SDS-PAGE and visualization by phosphorimaging. In $A-C,{ }^{32} \mathrm{P}$-labeled Prp8 fragments released by TEV protease cleavage are annotated following the same scheme as in Figure 2C. (B) Visualization of the cross-link between the 5'SS and the central region of Prp8 (residues 1281-1471) using Prp8 with a PreS protease site at 1281 and a TEV protease site at 1471. After cross-linking and capture, the sample was divided into four aliquots and incubated in the presence of proteases as indicated before fractionation by SDS-PAGE and visualization by phosphorimaging (left, 3\%-8\% polyacrylamide; right, 4\%-12\% polyacrylamide). The positions of unlabeled molecular weight markers are shown to the left of each gel. (C) Additional mapping data for cross-links between 5'SS-1 and Prp8, and comparison with cross-links between U5 snRNA (nucleotide 97) and Prp8. The position of the TEV protease site in Prp8 is indicated below each pair of lanes. After cross-linking and capture, the samples were divided into two aliquots and incubated with or without TEV protease before fractionation by SDS-PAGE and visualization by phosphorimaging. (Inset) Cartoon of the Prp8 protein, showing the array of TEV sites and summarizing the cross-link mapping data presented in $A-C$. 

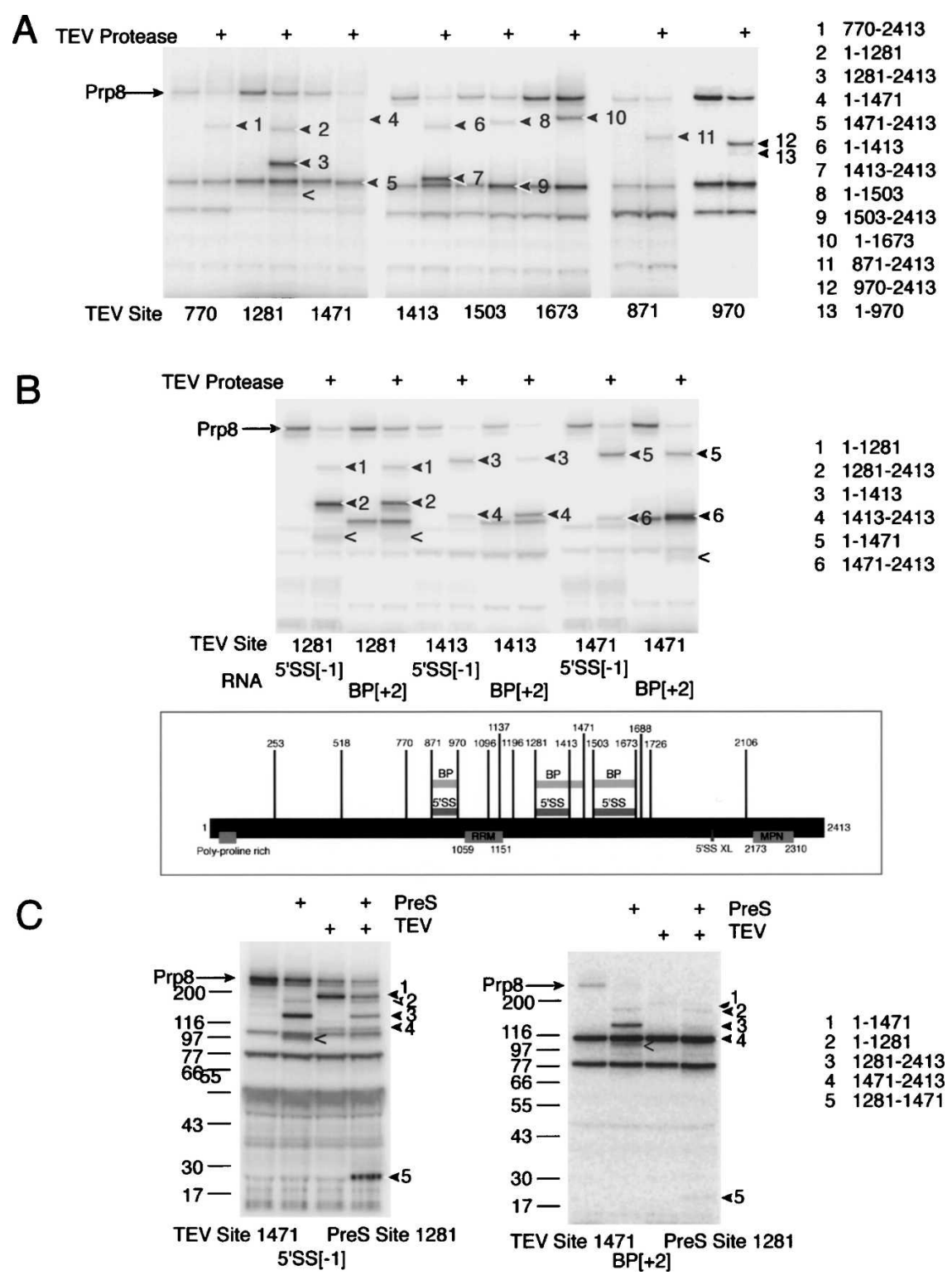

FIGURE 4. Prp8 interactions with the intron branch point. (A) Analysis of cross-links between $\operatorname{Prp} 8$ and the intron branch point in actin pre-mRNA, using a photocross-linker at position $\mathrm{BP}+2$. The position of the TEV protease site in Prp8 is indicated below each pair of lanes. After cross-linking and capture, the samples were divided into two aliquots and incubated with or without TEV protease before fractionation by SDS-PAGE and visualization by phosphorimaging. In $A-C{ }^{32} \mathrm{P}$-labeled Prp8 fragments released by TEV protease cleavage are annotated following the same scheme as in Figure 2C. (B) Comparison between $5^{\prime}$ SS and BP cross-linking patterns visualized by cleavage at TEV protease sites in the central region of Prp8. The position of the TEV protease site in Prp8 is indicated below each pair of lanes. After cross-linking and capture, the samples were divided into two aliquots and incubated with or without TEV protease before fractionation by SDS-PAGE and visualization by phosphorimaging. $(C)$ Comparison between 5'SS and BP cross-linking in the central region of Prp8 (residues 1281-1471) using Prp 8 with a PreS protease site at 1281 and a TEV protease site at 1471 . After crosslinking and capture, the sample was divided into four aliquots and incubated in the presence of proteases as indicated before fractionation by SDS-PAGE and visualization by phosphorimaging. The positions of unlabeled molecular weight markers are shown to the left of each gel. The identities of the labeled proteins of $80 \mathrm{kDa}$ and $115 \mathrm{kDa}$ (BP gel) are unknown. (Inset) Cartoon of the Prp8 protein, showing the array of TEV sites and summarizing the cross-link mapping data presented in $A-C$. incubating splicing reactions for $5 \mathrm{~min}$ at $23^{\circ} \mathrm{C}$, and the cross-links in radiolabeled Prp8 were then resolved using the proteolytic cleavage technique.

\section{Multiple interactions between Prp8 and the $5^{\prime}$ splice site}

After incubating radiolabeled Prp8 from $5^{\prime}$ SS-1 cross-linking reactions with TEV protease, one or more novel labeled protein bands appear (Fig. $3 \mathrm{~A}, \mathrm{C})$. Cleavage at 518, 770, 871, 1673, 1726, and 2106 in each case generates a single labeled polypeptide, indicating that the major cross-links lie between 871 and 1673. Cleavage at any of the sites between 871 and 1673 (970, 1281, $1413,1471,1503)$ results in both cleavage products being labeled, so this region of Prp8 contains at least two cross-links (Fig. 3A,C). Closer inspection of the labeling pattern produced by cleavage at 1281, 1413,1471, and 1503 suggests that there may in fact be three cross-linking sites in the central region of Prp8. The upstream site is relatively weak, but is clearly visualized by cleavage at 1281 , releasing labeled 11281 (minor band) and 1281-2413 (major band). It is striking that after cleavage at 1413 or 1471, however, most of the radiolabel is now in the Nterminal fragment (1-1413/1471) and the C-terminal fragment becomes the minor band. This suggests that there must be a strong cross-link in the region 1281-1413. In addition, since cleavage at 1503 labels both polypeptides, but cleavage at 1673 labels only $1-1673$, a third cross-link must lie in this interval (1503-1673). This is the same region that cross-linked to nucleotide 54 of U6 snRNA (Fig. 2A).

We have confirmed the presence of a cross-link between 1281 and 1471 by creating an additional prp8 allele with a site for PreS at 1281 and a site for TEV protease at 1471. Cleavage with PreS alone gave rise to labeled 1-1281 and 1281-2413 products, as expected (Fig. 3B; cf. Fig. 3A for cleavage by TEV at the same position). Cleavage with TEV alone produced 1-1471 and 1471-2413 products (Fig. 3B; cf. Fig. 3A). Signifi- 
cantly, when TEV and PreS proteases were used together a novel, labeled product appears: This is the $22-\mathrm{kDa} 1281-$ 1471 polypeptide, confirming that the 5'SS-1 4-thioU residue cross-links with three discrete regions of Prp8. Interestingly, the central 5'SS-1 cross-link maps to the same region of Prp8 as one of the U5 Loop 1 (97) cross-links. The position of the cross-link mapped upstream of 1281 (Fig. 3A) has been the most difficult to ascertain more precisely, in part because it is relatively weak. Comparison of the patterns of labeled proteins produced by cleavage at 871 after cross-linking with U5 Loop 1 [97] and 5'SS-1 (Fig. 3C) clearly shows that all 5'SS-1 cross-links lie downstream of 871 whereas U5 Loop 1 [97] cross-links lie both upstream and downstream of 871. Cleavage at 970 (Fig. 3C) and several other positions between 970 and 1281 (data not shown) in every case produces a poorly labeled $\mathrm{N}$-terminal fragment and a strongly labeled downstream fragment, indicating that the minor upstream 5'SS-1 cross-link lies between 871 and 970 .

In summary we have detected and mapped contacts between the 5'SS and three noncontiguous regions of the Prp8 sequence: 871-970, 1281-1413, and 1503-1673. The last two of these regions also contact the U5 snRNA Loop 1 [97] and U6 snRNA [54], respectively. None of these crosslinks maps within the conserved Prp8 RRM (residues 10591151).

\section{Interactions of the branch site with Prp8 mirror those of the $5^{\prime}$ splice site}

Proteolytic mapping data for radiolabeled Prp8 generated using actin pre-mRNA with a 4 -thioU residue 2 nucleotides downstream of the intron branch site $(\mathrm{BP}+2)$ are presented in Figure 4A-C. Interestingly, the results reveal a pattern of cross-links that closely parallels that produced by the 5'SS-1 photocross-linker. Cleavage at 770 or 871 releases a single labeled fragment (770-2413 or 871-2413) and so does cleavage at 1673 (producing 1-1673). Also, after cleavage in the central region of Prp8 at sites from 1281 to 1503 both of the digestion products are labeled (Fig. 4A,B) as shown for Prp8 labeled by the 5'SS cross-linker (see above).

The close similarity between the $5^{\prime} \mathrm{SS}-1$ and $\mathrm{BP}+2$ crosslink patterns is illustrated in the data shown in Figure 4B. After cleavage of 5'SS and BP-labeled Prp8 at 1281 both the $\mathrm{N}$ - and C-terminal Prp8 fragments are labeled, the C-terminal fragment more strongly. Following cleavage of the BPlabeled Prp8 at 1413 or 1471, however, the 5'SS-labeled and BP-labeled Prp8 give different patterns: For BP the C-terminal fragment is still strongly labeled, whereas for $5^{\prime} \mathrm{SS}$ it is the $\mathrm{N}$-terminal fragment that is strongly labeled. This suggests that the strong $5^{\prime} \mathrm{SS}$ cross-link in the 1281-1471 region is absent or less abundant in BP-labeled Prp8. Consistent with this, when the putative central cross-link (1281-1471) from $\mathrm{BP}+2$ is displayed by simultaneous cleavage with PreS and TEV proteases at 1281 and 1471, respectively, the re- sulting 22-kDa polypeptide is only barely labeled (Fig. 4C). Precisely echoing the situation for 5'SS-1, cross-linking with the $\mathrm{BP}+2$ pre-mRNA also results in formation of a minor cross-link upstream of 1281 (Fig. 4A) and, given that cleavage at 871 produces only a single labeled fragment (871-2413), this cross-link must lie between 871 and 1281. Echoing the situation for 5'SS-1 cross-links, cleavage at 970 and other positions between 970 and 1281 (data not shown) yields a minor $\mathrm{N}$-terminal product and a strongly labeled C-terminal product, mapping this minor $\mathrm{BP}+2$ cross-link between 871 and 970 . In summary the contacts between Prp8 and BP+2 map to three distinct regions of the protein, essentially identical to the 5'SS-1 cross-linking pattern: 871-970, 1281-1471, and 1503-1673. However the relative intensities of labeling of the three regions differ between 5'SS- and BP-derived cross-links.

\section{DISCUSSION}

The proteolytic mapping analysis presented here gives us a detailed picture of multiple Prp8-RNA contacts in snRNPs and spliceosomes (summarized in Fig. 5). The RNA contacts that we have mapped are restricted to the central region of Prp8. This contrasts neatly with existing protein interaction data for Prp8 that indicate multiple protein binding sites concentrated near the $\mathrm{N}$ and $\mathrm{C}$ termini (for review, see Grainger and Beggs 2005). It is striking that the 5'SS and BP both make contacts with the same set of three noncontiguous segments of Prp8. This makes sense in functional terms, given that the $5^{\prime} \mathrm{SS}$ and BP must necessarily be juxtaposed for catalysis; a cross-linker in either sequence might therefore be expected to target similar sites in a protein closely associated with the catalytic core. In principle, these three regions of Prp8 could contact the premRNA simultaneously, or they might do so sequentially in different functional states of the spliceosome. Our analysis of the chronology of splicing reactions showed that 5'SS cross-link formation correlates well with the catalytic steps of splicing (data not shown) but has not revealed clear differences in cross-linking kinetics between the three regions of Prp8. Therefore 5'SS contacts with a triad of discrete segments of Prp8 may instead reflect the tertiary fold of the protein around the spliceosome's RNA core. Further analysis of 5'SS and BP cross-links to Prp8 will be essential to demonstrate the functional significance of the Prp8-RNA interactions underlying the complex pattern of cross-links. In particular it will be crucial to establish the relationship between individual Prp8-substrate contacts and the catalytic steps of splicing. In any case it is interesting to note that two of the segments of Prp8 that harbor 5'SS/BP cross-links also contact invariant residues in U5 and U6 snRNAs in reconstituted snRNP and tri-snRNP particles, respectively (Fig. 5). This is potentially significant since these U5 and U6 residues-U97 in the U5 snRNA Loop 1 and U54 in U6 snRNA—are believed to be close to 


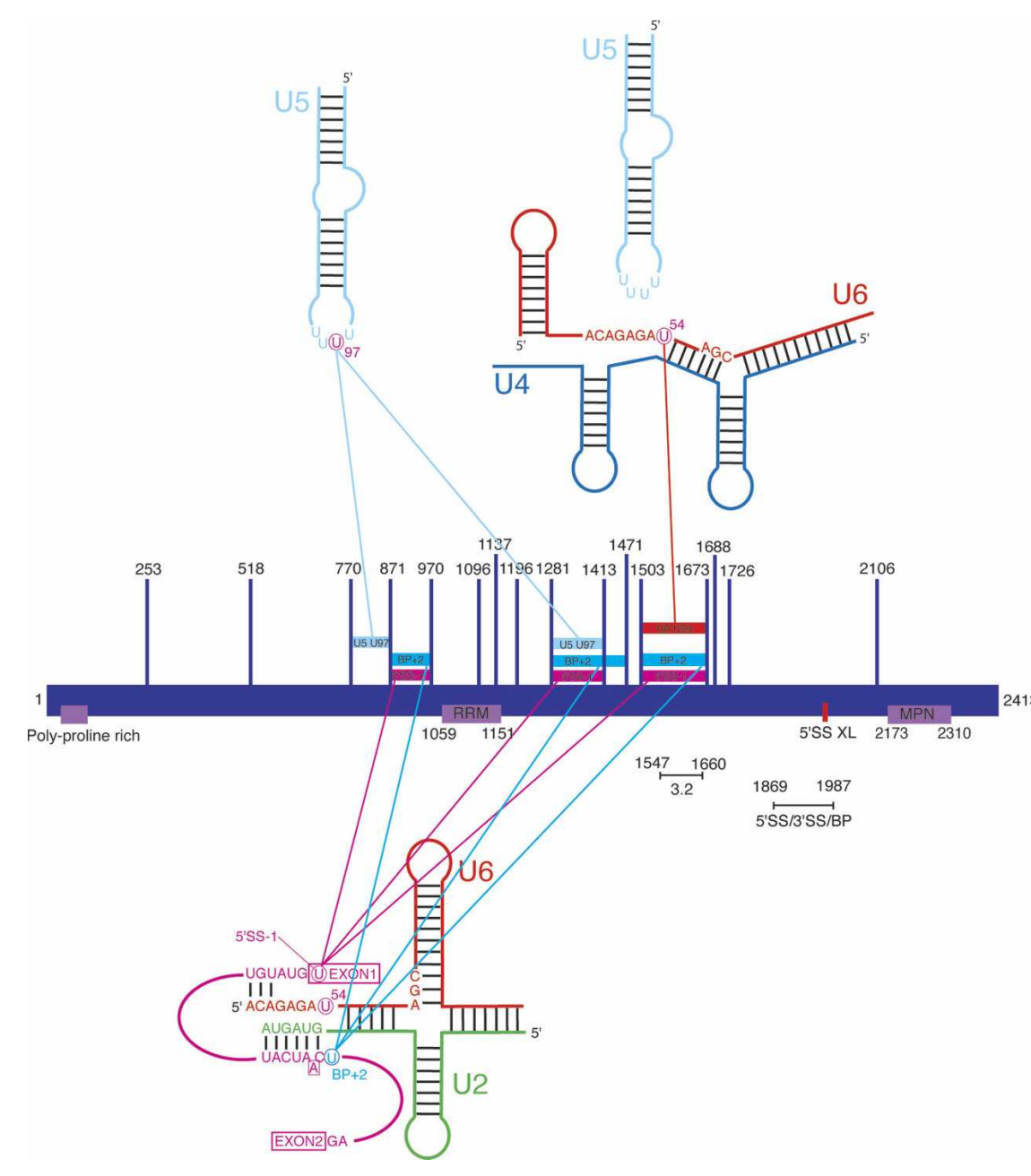

FIGURE 5. TEV protease mapping data for Prp8, showing the regions of the protein that cross-link to crucial snRNA and pre-mRNA residues. The TEV protease sites used for mapping RNA cross-links in Prp8 are indicated. Colored bars indicate regions where RNA cross-links reside, connected to the originating 4-thioU cross-linker by colored lines. U5 cross-links originate in U5 snRNPs, U6 cross-links from U4/U6.U5 tri-snRNPs, and the 5'SS and BS cross-links originate in spliceosomes. U5 snRNA is omitted from the spliceosome structure (shown below the Prp8 primary structure cartoon) for clarity. (RRM) putative RNA recognition motif (Grainger and Beggs 2005). (MPN) Mpr-1, Pad-1, N-terminal domain. The 5'SS cross-link mapped in hPrp8 is also indicated (5'SS XL; residues 1966-1970). Region 3.2 is linked genetically to 3'SS suppression (Umen and Guthrie 1996), and the region labeled 5'SS/ 3 'SS/BP is linked genetically to the transition between first and second catalytic step conformations of the spliceosome (Query and Konarska 2004).

the $5^{\prime}$ SS (and BP) in active spliceosomes (Newman and Norman 1992; Kandels-Lewis and Seraphin 1993; Lesser and Guthrie 1993; Sontheimer and Steitz 1993). This may indicate that some Prp8 interactions with U5 and U6 residues in tri-snRNPs survive the conformational changes that accompany spliceosome activation.

There is a discrepancy between the cross-link mapping data presented here and the result of an earlier study of the RNA interactions of hPrp8 (Reyes et al. 1999). These authors used a classical chemical and enzymatic fragmentation strategy to precisely map a cross-link between hPrp8 and the conserved 5'SS GU within splicing complex B in
HeLa cell extract. The data placed the cross-link near the $\mathrm{C}$ terminus of hPrp8, in a five-residue sequence corresponding to amino acids $1966-1970$ in yeast Prp8; surprisingly this sequence is not conserved from human to yeast. As discussed above, in yeast spliceosomes all the cross-links generated using the 5 'SS1 and $\mathrm{BP}+2$ cross-linkers mapped upstream of 1673 in Prp8. Furthermore all the cross-links from a photocrosslinker placed at 5'SS+2 (position 2 of the intron) also mapped upstream of 1673 , including one in the 1503-1673 region colocalized with cross-links to 5'SS-1, BP+2, and U6 [U54] (data not shown). In addition preliminary mapping of cross-links from a photocrosslinker placed at the 3'SS also showed that all detectable cross-links were upstream of position 1726 in Prp8 (data not shown). Given that a great deal of evidence (for review, see Collins and Guthrie 2000) suggests that the organization of the yeast and human catalytic cores is substantially similar, and that the hPrp8 and yPrp8 orthologs are so closely related (Grainger and Beggs 2005), it seems unlikely that there would be major differences between Prp8-spliceosomal core interactions in the two systems. It is possible that the Prp8-5'SS contact mapped in the Hela system (Reyes et al. 1999) derives from a conformation of the spliceosome that is not prevalent in the yeast system. It will be interesting to see if blocking yeast spliceosomes at specific points in the process traps additional contacts between the 5'SS and Prp8.

Three recognized functional domains have so far been identified in Prp8 by bio-informatic analysis (Grainger and Beggs 2005): a nuclear localization signal (NLS) sequence near the $\mathrm{N}$ terminus, an RRM (residues 1059-1151), and an Mpr1 Pad1 N-terminal domain (MPN; residues 21732310) that is related to Jab1/MPN domains found in some de-ubiquitinating enzymes. Unexpectedly we isolated functional prp8 alleles with TEV protease site insertions at 1096 and 1102 within the RRM. However, closer examination of the RRM and its secondary structure shows that these inserts fall within loop 3 of the RRM fold, which is highly variable in known RNA-binding RRM domains (Varani and Nagai 1998). Therefore these insertions do not rule out an RNA-binding function for Prp8's 
RRM; the nine-residue Loop 3 predicted in $\operatorname{Prp} 8$ may simply be extended without compromising RRM function. A similar situation may apply to the MPN domain (21732310): Three TEV insertions fall within this domain, but again they map to a variable region (Tran et al. 2003; Grainger and Beggs 2005) and therefore may not affect the domain's structure or function. At present it is not possible to ascribe specific functions to the MPN and RRM domains in Prp8. It is clear that all the RNA contacts that we have characterized so far lie outside the RRM, so perhaps this domain binds other RNA sequences or simply fails to cross-link to the pre-mRNA and snRNA positions that we have surveyed so far. Some RRM domains have been shown to bind proteins (Kielkopf et al. 2001; Selenko et al. 2003), but the Prp8 RRM does not appear to match the features that are proposed to define protein-binding RRM domains (Kielkopf et al. 2004).

Prp8 has been widely studied using a variety of genetic approaches and the sequence is now extensively annotated (Grainger and Beggs 2005). In addition to genetic interactions with U4 and U6 snRNAs (Kuhn et al. 1999, 2002; Kuhn and Brow 2000) multiple prp8 alleles can suppress the effects of both 5'SS and 3'SS mutations (Collins and Guthrie 1999; Siatecka et al. 1999), suggesting that Prp8 affects the function of the spliceosome's catalytic center. In fact the same SS suppressor alleles can also act as suppressors of BP mutations, so all three substrate sequences involved in the catalysis of splicing interact genetically with PRP8 (Query and Konarska 2004). In principle, suppression of SS/BP mutations could reflect altered direct contacts between Prp8 and SS or BP nucleotides. However, the large number and scattered distribution of SS/BP suppressor alleles of $\operatorname{prp} 8$ and the broad spectrum of mutations that are suppressed are more compatible with a model of suppression in which the second-step core catalytic structure is selectively stabilized, resulting in enhanced catalysis of the second step of splicing (Query and Konarska 2004). In this scenario the sites of prp8 SS/BP suppressor mutations may be more or less remote from the Prp8 sequences that actually contact the catalytic core RNAs. This would place a premium on biochemical data of the sort we have presented here for 5'SS and BP RNA interactions with Prp8 in spliceosomes: Such information may identify regions of Prp8 that directly contact the sites of chemistry (Collins and Guthrie 2000). Currently the best candidate "domain" for splicing cofactor activity is the region defined by the TEV protease sites at 1503 and 1673 . This interval is the site of cross-links from nucleotide U54 in U6 snRNA, as well as 5'SS-1, 5'SS+2 and BP+2 cross-linkers in the pre-mRNA (Figs. 2-4; data not shown). It also corresponds closely to a region of exceptional sequence conservation (region 3.2, 1547-1660; Grainger and Beggs 2005) that includes a dense cluster of 3'SS suppressor mutations (Umen and Guthrie 1996). It will be interesting to analyze the interactions of catalytic core RNAs with this crucial segment of Prp8 in more detail.

\section{MATERIALS AND METHODS}

\section{Transposon construction}

Complementary oligonucleotides AW42 GATCCTGTCTCTTAT ACACATCTGGCGCGCCGTAGAAAATTTATATTTTCAAGGAG ATGTGTATAAGAGACAG and AW43 GATCCTGTCTCTTATAC ACATCTCCTTGAAAATATAAATTTTCTACGGCGCGCCAGATG TGTATAAGAGACAG were 5'-phosphorylated, annealed together, and inserted into the BamHI site of pBluescript KS+ (Stratagene). This synthetic insert encodes the TEV protease cleavage sequence ENLYFQG and an AscI site, flanked by the "Outer End" recognition sequences for Tn5 transposase (Goryshin and Reznikoff 1998). To follow transposition reaction products, a removable kanamycin resistance cassette (Kan) was then inserted at the unique AscI site in the TEV transposon. The complete TEV [Kan] transposon including the kanamycin resistance cassette was then amplified by PCR using primers FTA1 CCCTCGAGGTCG ACGGTATCG and RTA1 ATAGGGCGAATTGGAGCTCCA specific for sequences flanking the transposon.

\section{Random insertion of TEV protease sites into Prp8}

For random insertion of TEV $[\mathrm{Kan}]$ transposons into the entire ORF, the target DNA was pRS314, carrying a $9.6-\mathrm{Kb}$ yeast genomic DNA fragment including the PRP8 coding sequence plus $5^{\prime}$ and $3^{\prime}$ flanking sequences. Unique sites for NheI and MluI were first introduced at the $5^{\prime}$ and $3^{\prime}$ ends of the PRP 8 ORF by site-directed mutagenesis (Kunkel 1985) and a Protein A epitope tag was inserted at the $\mathrm{N}$ terminus. Target DNA $(1 \mu \mathrm{g})$ was incubated in a $10 \mu \mathrm{L}$ reaction with a molar equivalent of the TEV [Kan] transposon in the presence of $0.1 \mathrm{U} / \mu \mathrm{L}$ EZ::TN transposase (Epicentre) at $37^{\circ} \mathrm{C}$ for $2 \mathrm{~h}$ according to the manufacturer's instructions. The reaction was stopped by addition of $1 \mu \mathrm{L} 1 \%$ SDS followed by heating to $70^{\circ} \mathrm{C}$ for $10 \mathrm{~min}$. Aliquots $(1 \mu \mathrm{L})$ of the transposition reaction were transformed by electroporation into XL10 Gold cells (Stratagene), and plasmids that had been targeted by the transposon were recovered by selection for ampicillin and kanamycin resistance. Plasmid DNA was prepared from pooled transformants and the PRP8 ORF was excised by digestion with NheI and MluI, gel purified, and recloned into NheI + MluI "gapped" pRS314- $P R P 8$ vector, again selecting for ampicillin and kanamycin resistance. Plasmid DNA was prepared from pooled transformants, to produce a plasmid library in which each individual carries a TEV (Kan) transposon inserted at random somewhere in the PRP8 ORF.

An aliquot of the plasmid library was digested with AscI to excise the kanamycin resistance cassette, and the linearized plasmid was gel purified, recircularized by ligation, and transformed by electroporation into XL10 Gold cells, this time selecting for ampicillin resistance. Plasmid DNA was prepared from the pooled cells, giving a library of pRS314- $P R P 8$ plasmids, each carrying a 69-bp insert placed at random in the ORF, marked by a unique AscI site. Five of the six possible reading frames for TEV transposon insertion are closed by stop codons in the transposon itself. The single open reading frame introduces a short, internal peptide tag (LSLIHIW RAVENLYFQGDVYKRQ) that includes the cleavage sequence for TEV protease (ENLYFQ/G, where / denotes the site of cleavage).

Functional copies of $\operatorname{prp} 8$ were identified by plasmid shuffle on plates containing 5-FOA after transformation into the yeast strain 
SC261 8 8B1 (Mata ura3-52 leu2 trp1 pep4-3 prb1-1132 prc1-407 prp8:: Blasticidin [pRS316-PRP8]). The location of each TEV protease site was determined by restriction mapping and DNA sequencing.

\section{Site-specific labeling and ligation of snRNAs and pre-mRNAs}

U6 snRNA with a single ${ }^{32} \mathrm{P}$ label and adjacent 4 -thioU or $\mathrm{U}$ at position 54 was made by ligation with T4 DNA ligase (Moore and Sharp 1992) using the following components: U6 (1-53), $5^{\prime}-\left[{ }^{32} \mathrm{P}\right]-$ U6 (54-77), U6 (78-112), and antisense bridge oligonucleotide GTAAAACGGTTCATCCTTATGCAGGGGAACTGCTGATCATC TCTGTATTGTTTC. U6 (1-53) was made by T7 transcription and ribozyme cleavage using a construct containing U6 (1-53) embedded between hammerhead and hepatitis delta ribozymes. U6 (54-77) and U6 (78-112) are synthetic RNAs, the latter with an unlabeled $5^{\prime}$ phosphate added during synthesis.

U5 snRNA with a single ${ }^{32} \mathrm{P}$ label and adjacent 4 -thioU or $\mathrm{U}$ at position 97 was made by ligation with T4 DNA ligase using the following components: U5 (97-112), U5 (113-215), and antisense bridge oligonucleotide TCTATGGAGACAACACCCGGAT GGTTCTGGTAAA. U5 (97-112) was a synthetic RNA, and U5 (113-215) was made by T7 transcription primed with GMP to introduce an unlabeled $5^{\prime}$ phosphate. The ligated U5 (97-215) RNA was gel purified, $5^{\prime}-\left[{ }^{32} \mathrm{P}\right]$-phosphorylated, and ligated to a T7 transcript comprising U5 (1-96) using T4 RNA ligase (New England Biolabs; final concentration $1 \mathrm{U} / \mu \mathrm{L}$ ).

Actin pre-mRNA with a single ${ }^{32} \mathrm{P}$ label and adjacent 4-thioU or $\mathrm{U}$ at $5^{\prime} \mathrm{SS}-1$ was made by ligation with T4 DNA ligase using the following components: actin (1-20), actin (21-37), actin (38exon 2), and antisense bridge oligonucleotide TCTTACAGTTAAA TGGGATGGTCCAAGCGCTAGAACATACAAGAATCCATTGTT AATTCAG. Actin (1-20) is a synthetic RNA exon 1 sequence (CUGAAUUAACAAUGGAUUCU) extending to nucleotide 5 'SS2. Actin (21-37) (UGUAUGUUCUAGCGCUU) begins with 4thioU or $\mathrm{U}$ and was $5^{\prime}-\left[{ }^{32} \mathrm{P}\right]$-phosphorylated. Actin (38-exon 2) is a T7 transcript initiating at intron position 17 and extending through the intron into exon 2; T7 transcription was primed with GMP to introduce an unlabeled $5^{\prime}$ phosphate.

Actin pre-mRNA with a single ${ }^{32} \mathrm{P}$ label and adjacent 4 -thioU or $\mathrm{U}$ at $\mathrm{BP}+2$ was made by ligation with $\mathrm{T} 4 \mathrm{DNA}$ ligase using the following components: actin (1-283), actin (284-325), actin (326-exon 2), and antisense bridge oligonucleotide CCAAAGCAGCAACCACTAAAC ATATAATATAGCAACAAAAAGAATGAAGCAATCGAAGTTAGT ACATGAGAC. Actin (1-283) was made by T7 transcription and ribozyme cleavage using a construct containing actin sequences extending from exon 1 to the final $\mathrm{C}$ of the TACTAAC branch point sequence, upstream of a hepatitis delta ribozyme. Actin (284-325) (UUCGAUUGCUUCAUUCUUUUUGUUGCUAUAUUAUAUGU UUAG) begins with 4-thioU or $U$ and was $5^{\prime}-\left[{ }^{32} \mathrm{P}\right]$-phosphorylated prior to ligation. Actin (326-exon 2) (UGGUUGCUGCUUUGGUU AUUG AUAAC) has an unlabeled $5^{\prime}$ phosphate.

\section{U5 and U6 snRNP depletion and reconstitution methods}

U5 snRNP reconstitution was performed essentially as described (O’Keefe and Newman 1998) using splicing extracts from shuffled derivatives of the yeast strain SC261.35 (Mata ura3-52 leu2 trp1 pep4-3 prb1-1132 prc1-407 snr7-rok8 prp8::Blasticidin [pRS316PRP8]), in which the genomic copy of the SNR7 gene encoding U5 snRNA was modified by introduction of a 30-nt insertion into the sequence encoding stem 1 of U5 snRNA. The modified form of U5 allows targeted depletion and functional reconstitution of U5 snRNPs (O'Keefe et al. 1996). This snr7 mutant proved to be synthetically lethal with certain TEV-site-tagged prp8 alleles, so in these cases reconstitution of U5 snRNPs was achieved by treatment of extracts from SNR7 shuffle strains with RNase A (final concentration $0.5 \mathrm{ng} / \mu \mathrm{L}$ ) at $37^{\circ} \mathrm{C}$ for $30 \mathrm{~min}$, followed by addition of 10 mM DTT, RNasin (final concentration $1 \mathrm{U} / \mu \mathrm{L}$ ) and site-specifically labeled U5 snRNA (final concentration $1 \mathrm{nM}$ ). The RNase $\mathrm{H}$ and RNase A-mediated depletion methods were used in parallel on several splicing extracts containing TEV-site-tagged Prp8; both methods produced identical TEV cleavage mapping information for U5 Loop-Prp8 cross-links (data not shown). U6 snRNP depletion and reconstitution was performed using a modification (R.J. Lin, pers. comm.) of the original method (Fabrizio et al. 1989) as follows: Extracts were incubated under splicing conditions for $30 \mathrm{~min}$ at $30^{\circ} \mathrm{C}$ in the presence of $1 \mu \mathrm{M}$ d 1 oligonucleotide (CTGTATTGTTTCAAA). Anti-d1 oligonucleotide (TTTGAAA CAATACAG) was added (final concentration $1 \mu \mathrm{M}$ ), and the reaction was incubated at $30^{\circ} \mathrm{C}$ for $5 \mathrm{~min}$ before addition of sitespecifically labeled U6 snRNA (final concentration $1 \mathrm{nM}$ ).

\section{RNA-protein cross-linking and cross-link analysis}

Splicing extracts were prepared from selected shuffled strains (Lin et al. 1985) expressing TEV transposon-tagged versions of Prp8, and these were shown to have normal splicing activity using actin premRNA as substrate (data not shown). For detection and mapping of RNA-protein cross-links from specific 4-thioU residues in the premRNA, splicing reactions (Lin et al. 1985) were assembled on ice, typically containing $0.2 \mathrm{pmol}$ pre-mRNA in a $200-\mu \mathrm{L}$ reaction. Splicing reactions were typically incubated at $23^{\circ} \mathrm{C}$ for $5-10 \mathrm{~min}$ and UV irradiated ( $365 \mathrm{~nm} \mathrm{UV}$ ) at $4^{\circ} \mathrm{C}$ for $5 \mathrm{~min}$ (Model B100AP lamp; UV Products). The reaction was diluted 10-fold in IP150 buffer (10 mM Tris- $\mathrm{Cl}$ at $\mathrm{pH} 8.0,150 \mathrm{mM} \mathrm{NaCl}, 0.1 \%$ Nonidet NP40) and incubated with gentle mixing at $4^{\circ} \mathrm{C}$ for $2 \mathrm{~h}$ with $10 \mu \mathrm{L}$ IgG-sepharose beads (Pharmacia) to capture complexes containing Prp8. The beads were washed twice with cold IP150 buffer and twice with $1 \times$ TEV buffer ( $50 \mathrm{mM}$ Tris-Cl at pH 8.0, $0.5 \mathrm{mM}$ EDTA, $5 \mathrm{mM}$ DTT) and resuspended in $100 \mu \mathrm{L} 1 \times \mathrm{TEV}$ buffer. This sample was divided into two aliquots, $1 \mu \mathrm{L}$ TEV protease (Invitrogen; $10 \mathrm{U} / \mu \mathrm{L}$ ) was added to one aliquot, and the samples were incubated for $16-40 \mathrm{~h}$ at $18^{\circ} \mathrm{C}$. Digestions with PreScission Protease (Amersham Biosciences, $2 \mathrm{U} / \mu \mathrm{L})$ were performed likewise in $1 \times \mathrm{TEV}$ buffer. Following protease cleavage, $2 \mu \mathrm{L}$ RNase T1 (Merck; $10 \mathrm{U} / \mu \mathrm{L}$ ) were added and the samples were incubated at $37^{\circ} \mathrm{C}$ for $1 \mathrm{~h}$. The IgG-sepharose beads were washed twice in cold IP150 buffer, and proteins were eluted from the beads in $10 \mu \mathrm{L}$ LDS sample buffer for $2 \mathrm{~min}$ at $90^{\circ} \mathrm{C}$. Proteins were fractionated by $3 \%-8 \%$ or $4 \%-12 \%$ SDS-PAGE (Novex Gels; Invitrogen) and visualized by phosphorimaging.

\section{ACKNOWLEDGMENTS}

We thank Adam Wilkinson for his contributions to transposon design and construction. We also thank Kiyoshi Nagai, Hugh 
Pelham, Jean Beggs, Richard Grainger, and Daniel PomeranzKrummel for comments on the manuscript. This work was supported by the MRC.

Received September 13, 2005; accepted November 23, 2005.

\section{REFERENCES}

Boulanger, S.C., Belcher, S.M., Schmidt, U., Dib-Hajj, S.D., Schmidt, T., and Perlman, P.S. 1995. Studies of point mutants define three essential paired nucleotides in the domain 5 substructure of a group II intron. Mol. Cell. Biol. 15: 4479-4488.

Chiara, M.D., Gozani, O., Bennett, M., Champion-Arnaud, P., Palandjian, L., and Reed, R. 1996. Identification of proteins that interact with exon sequences, splice sites, and the branchpoint sequence during each stage of spliceosome assembly. Mol. Cell. Biol. 16: 3317-3326.

Chiara, M.D., Palandjian, L., Feld Kramer, R., and Reed, R. 1997. Evidence that U5 snRNP recognizes the $3^{\prime}$ splice site for catalytic step II in mammals. EMBO J. 16: 4746-4759.

Collins, C.A. and Guthrie, C. 1999. Allele-specific genetic interactions between Prp8 and RNA active site residues suggest a function for Prp8 at the catalytic core of the spliceosome. Genes \& Dev. 13: 1970-1982.

- 2000. The question remains: Is the spliceosome a ribozyme? Nat. Struct. Biol. 7: 850-854.

Cortes, J.J., Sontheimer, E.J., Seiwert, S.D., and Steitz, J.A. 1993. Mutations in the conserved loop of human U5 snRNA generate use of novel cryptic $5^{\prime}$ splice sites in vivo. EMBO J. 12: 5181-5189.

Dix, I., Russell, C.S., O'Keefe, R.T., Newman, A.J., and Beggs, J.D. 1998. Protein-RNA interactions in the U5 snRNP of Saccharomyces cerevisiae. RNA 4: 1675-1686.

Fabrizio, P., McPheeters, D.S., and Abelson, J. 1989. In vitro assembly of yeast U6 snRNP: A functional assay. Genes \& Dev. 3: 2137-2150.

Goryshin, I.Y. and Reznikoff, W.S. 1998. Tn5 in vitro transposition. J. Biol. Chem. 273: 7367-7374.

Grainger, R.J. and Beggs, J.D. 2005. Prp8 protein: At the heart of the spliceosome. RNA 11: 533-557.

Hilliker, A.K. and Staley, J.P. 2004. Multiple functions for the invariant AGC triad of U6 snRNA. RNA 10: 921-928.

Hodges, P.E., Jackson, S.P., Brown, J.D., and Beggs, J.D. 1995. Extraordinary sequence conservation of the PRP8 splicing factor. Yeast 11: 337-342.

Huppler, A., Nikstad, L.J., Allmann, A.M., Brow, D.A., and Butcher, S.E. 2002. Metal binding and base ionization in the U6 RNA intramolecular stem-loop structure. Nat. Struct. Biol. 9: 431-435.

Kandels-Lewis, S. and Seraphin, B. 1993. Involvement of U6 snRNA in 5' splice site selection. Science 262: 2035-2039.

Kielkopf, C.L., Rodionova, N.A., Green, M.R., and Burley, S.K. 2001. A novel peptide recognition mode revealed by the X-ray structure of a core U2AF35/U2AF65 heterodimer. Cell 106: 595-605.

Kielkopf, C.L., Lucke, S., and Green, M.R. 2004. U2AF homology motifs: Protein recognition in the RRM world. Genes \& Dev. 18: 1513-1526.

Kim, D.H. and Rossi, J.J. 1999. The first ATPase domain of the yeast $246-\mathrm{kDa}$ protein is required for in vivo unwinding of the U4/U6 duplex. RNA 5: 959-971.

Kuhn, A.N. and Brow, D.A. 2000. Suppressors of a cold-sensitive mutation in yeast U4 RNA define five domains in the splicing factor Prp8 that influence spliceosome activation. Genetics 155: 1667-1682.

Kuhn, A.N., Li, Z., and Brow, D.A. 1999. Splicing factor Prp8 governs U4/U6 RNA unwinding during activation of the spliceosome. Mol. Cell 3: 65-75.

Kuhn, A.N., Reichl, E.M., and Brow, D.A. 2002. Distinct domains of splicing factor Prp8 mediate different aspects of spliceosome activation. Proc. Natl. Acad. Sci. 99: 9145-9149.
Kunkel, T.A. 1985. Rapid and efficient site-specific mutagenesis without phenotypic selection. Proc. Natl. Acad. Sci. 82: 488-492.

Laggerbauer, B., Achsel, T., and Luhrmann, R. 1998. The human U5200kD DEXH-box protein unwinds U4/U6 RNA duplices in vitro. Proc. Natl. Acad. Sci. 95: 4188-4192.

Lesser, C.F. and Guthrie, C. 1993. Mutations in U6 snRNA that alter splice site specificity: Implications for the active site. Science 262: 1982-1988.

Lin, R.J., Newman, A.J., Cheng, S.C., and Abelson, J. 1985. Yeast mRNA splicing in vitro. J. Biol. Chem. 260: 14780-14792.

Luo, H.R., Moreau, G.A., Levin, N., and Moore, M.J. 1999. The human Prp8 protein is a component of both U2- and U12-dependent spliceosomes. RNA 5: 893-908.

Madhani, H.D. and Guthrie, C. 1992. A novel base-pairing interaction between $\mathrm{U} 2$ and U6 snRNAs suggests a mechanism for the catalytic activation of the spliceosome. Cell 71: 803-817.

Maroney, P.A., Romfo, C.M., and Nilsen, T.W. 2000. Functional recognition of $5^{\prime}$ splice site by U4/U6.U5 tri-snRNP defines a novel ATP-dependent step in early spliceosome assembly. Mol. Cell 6: 317-328.

McPheeters, D.S. and Muhlenkamp, P. 2003. Spatial organization of protein-RNA interactions in the branch site- ${ }^{\prime}$ splice site region during pre-mRNA splicing in yeast. Mol. Cell. Biol. 23: 41744186.

Moore, M.J. and Sharp, P.A. 1992. Site-specific modification of premRNA: The 2'-hydroxyl groups at the splice sites. Science 256: 992-997.

. 1993. Evidence for two active sites in the spliceosome provided by stereochemistry of pre-mRNA splicing. Nature 365: 364-368.

Newman, A.J. and Norman, C. 1992. U5 snRNA interacts with exon sequences at $5^{\prime}$ and $3^{\prime}$ splice sites. Cell 68: 743-754.

Newman, A.J., Teigelkamp, S., and Beggs, J.D. 1995. snRNA interactions at $5^{\prime}$ and $3^{\prime}$ splice sites monitored by photoactivated crosslinking in yeast spliceosomes. RNA 1: 968-980.

O'Keefe, R.T. and Newman, A.J. 1998. Functional analysis of the U5 snRNA loop 1 in the second catalytic step of yeast pre-mRNA splicing. EMBO J. 17: 565-574.

O'Keefe, R.T., Norman, C., and Newman, A.J. 1996. The invariant U5 snRNA loop 1 sequence is dispensable for the first catalytic step of pre-mRNA splicing in yeast. Cell 86: 679-689.

Padgett, R.A., Podar, M., Boulanger, S.C., and Perlman, P.S. 1994. The stereochemical course of group II intron self-splicing. Science 266: $1685-1688$.

Parker, R., Siliciano, P.G., and Guthrie, C. 1987. Recognition of the TACTAAC box during mRNA splicing in yeast involves base pairing to the U2-like snRNA. Cell 49: 229-239.

Peebles, C.L., Zhang, M., Perlman, P.S., and Franzen, J.S. 1995. Catalytically critical nucleotide in domain 5 of a group II intron. Proc. Natl. Acad. Sci. 92: 4422-4426.

Query, C.C. and Konarska, M.M. 2004. Suppression of multiple substrate mutations by spliceosomal prp8 alleles suggests functional correlations with ribosomal ambiguity mutants. Mol. Cell 14: $343-$ 354.

Raghunathan, P.L. and Guthrie, C. 1998. RNA unwinding in U4/U6 snRNPs requires ATP hydrolysis and the DEIH-box splicing factor Brr2. Curr. Biol. 8: 847-855.

Reyes, J.L., Kois, P., Konforti, B.B., and Konarska, M.M. 1996. The canonical GU dinucleotide at the $5^{\prime}$ splice site is recognized by p220 of the U5 snRNP within the spliceosome. RNA 2: 213-225.

Reyes, J.L., Gustafson, E.H., Luo, H.R., Moore, M.J., and Konarska, M.M. 1999. The C-terminal region of hPrp8 interacts with the conserved GU dinucleotide at the 5' splice site. RNA 5: 167-179.

Sashital, D.G., Cornilescu, G., McManus, C.J., Brow, D.A., and Butcher, S.E. 2004. U2-U6 RNA folding reveals a group II intron-like domain and a four-helix junction. Nat. Struct. Mol. Biol. 11: 1237-1242.

Selenko, P., Gregorovic, G., Sprangers, R., Stier, G., Rhani, Z., Kramer, A., and Sattler, M. 2003. Structural basis for the molecular recog- 
nition between human splicing factors U2AF65 and SF1/mBBP. Mol. Cell 11: 965-976.

Shevchenko, Y., Bouffard, G.G., Butterfield, Y.S., Blakesley, R.W., Hartley, J.L., Young, A.C., Marra, M.A., Jones, S.J., Touchman, J.W., and Green, E.D. 2002. Systematic sequencing of cDNA clones using the transposon Tn5. Nucleic Acids Res. 30: 2469-2477.

Siatecka, M., Reyes, J.L., and Konarska, M.M. 1999. Functional interactions of Prp8 with both splice sites at the spliceosomal catalytic center. Genes \& Dev. 13: 1983-1993.

Sigel, R.K., Vaidya, A., and Pyle, A.M. 2000. Metal ion binding sites in a group II intron core. Nat. Struct. Biol. 7: 1111-1116.

Sontheimer, E.J. and Steitz, J.A. 1993. The U5 and U6 small nuclear RNAs as active site components of the spliceosome. Science 262: 1989-1996.

Sun, J.S. and Manley, J.L. 1995. A novel U2-U6 snRNA structure is necessary for mammalian mRNA splicing. Genes \& Dev. 9: 843-854.

Teigelkamp, S., Newman, A.J., and Beggs, J.D. 1995. Extensive interactions of PRP8 protein with the $5^{\prime}$ and $3^{\prime}$ splice sites during splicing suggest a role in stabilization of exon alignment by U5 snRNA. EMBO J. 14: 2602-2612.

Tran, H.J., Allen, M.D., Lowe, J., and Bycroft, M. 2003. Structure of the Jab1/MPN domain and its implications for proteasome function. Biochemistry 42: 11460-11465.

Umen, J.G. and Guthrie, C. 1995a. A novel role for a U5 snRNP protein in 3' splice site selection. Genes \& Dev. 9: 855-868.

. 1995b. Prp16p, Slu7p, and Prp8p interact with the $3^{\prime}$ splice site in two distinct stages during the second catalytic step of premRNA splicing. RNA 1: 584-597.
1996. Mutagenesis of the yeast gene PRP8 reveals domains governing the specificity and fidelity of $3^{\prime}$ splice site selection. Genetics 143: 723-739.

Valadkhan, S. and Manley, J.L. 2001. Splicing-related catalysis by protein-free snRNAs. Nature 413: 701-707.

van Nues, R.W. and Beggs, J.D. 2001. Functional contacts with a range of splicing proteins suggest a central role for Brr2p in the dynamic control of the order of events in spliceosomes of Saccharomyces cerevisiae. Genetics 157: 1451-1467.

Varani, G. and Nagai, K. 1998. RNA recognition by RNP proteins during RNA processing. Annu. Rev. Biophys. Biomol. Struct. 27: 407-445.

Vidal, V.P., Verdone, L., Mayes, A.E., and Beggs, J.D. 1999. Characterization of U6 snRNA-protein interactions. RNA 5: 1470-1481.

Villa, T., Pleiss, J.A., and Guthrie, C. 2002. Spliceosomal snRNAs: $\mathrm{Mg}(2+)$-dependent chemistry at the catalytic core? Cell 109: 149152.

Wu, J. and Manley, J.L. 1989. Mammalian pre-mRNA branch site selection by U2 snRNP involves base pairing. Genes \& Dev. 3: $1553-1561$.

Wyatt, J.R., Sontheimer, E.J., and Steitz, J.A. 1992. Site-specific cross-linking of mammalian U5 snRNP to the $5^{\prime}$ splice site before the first step of pre-mRNA splicing. Genes \& Dev. 6: $2542-2553$

Yean, S.L., Wuenschell, G., Termini, J., and Lin, R.J. 2000. Metal-ion coordination by U6 small nuclear RNA contributes to catalysis in the spliceosome. Nature 408: 881-884. 

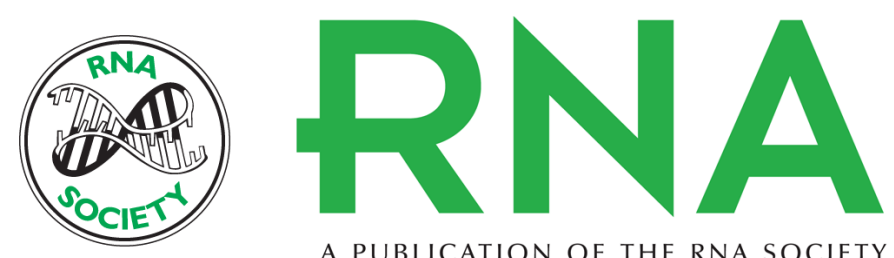

A PUBLICATION OF THE RNA SOCIETY

\section{Dissection of Prp8 protein defines multiple interactions with crucial RNA sequences in the catalytic core of the spliceosome}

IAN A. TURNER, CHRISTINE M. NORMAN, MARK J. CHURCHER, et al.

RNA 2006 12: 375-386

References This article cites 61 articles, 37 of which can be accessed free at:

http://rnajournal.cshlp.org/content/12/3/375.full.html\#ref-list-1

License

Email Alerting Receive free email alerts when new articles cite this article - sign up in the box at the Service top right corner of the article or click here. 